\title{
CATEGOREMAS INDÍGENAS Y DESIGNACIONES ARQUEOLÓGICAS EN EL NOROESTE ARGENTINO PREHISPÁNICO
}

\author{
INDIGENOUS CATEGOREMS AND ARCHAEOLOGICAL DESIGNATIONS \\ IN PREHISPANIC NORTHWEST ARGENTINA
}

\author{
María Cristina Scattolin ${ }^{1}$
}

\begin{abstract}
Las categorías usadas en las clasificaciones arqueológicas, de modo similar a las etnocategorías indígenas, son objeto de representaciones mentales por parte de los mismos investigadores. Por eso también pueden ser materia de estudio a investigar, tal como la antropología ha investigado los esquemas conceptuales de los indígenas. Una vigilancia metódica de las clasificaciones arqueológicas podría contribuir a extirpar valoraciones que persisten en la investigación científica. Esta idea se aplica al análisis del primer milenio d.C. en el valle de Santa María del noroeste argentino. Los resultados demuestran que las categorías de análisis en arqueología se imponen por la incorporación incontrolada de esquemas cognitivos indígenas y se emancipan de nuestro dominio por la repetición rutinaria más que por validación científica. Además, confirman que "lo que es cierto del pensamiento salvaje, es cierto de todo pensamiento culto" y ratifican la conveniencia de someter regularmente a revisión las categorías de análisis en arqueología.

Palabras claves: clasificaciones arqueológicas, categorías indígenas, noroeste argentino.
\end{abstract}

In a similar way to indigenous ethnocategories, categories used in archaeological classifications are an object of mental representations by researchers. Hence, they can be scrutinized also, just as anthropology has studied native conceptual schemes. A methodical review of archaeological classifications would reduce subjective valuations that persist in scientific research. This idea is applied to the analysis of the first millennium A.D. in the Santa María Valley, Northwest Argentina. The results show that archaeological categories are imposed by the uncontrolled incorporation of indigenous cognitive schemes and become emancipated from our control by routine repetition more than by scientific validation. This work confirms that "what is certain of the savage thought, is certain of all learned thought" and it ratifies the appropriateness of regularly subjecting archaeological categories to review.

Key words: Archaeological classifications, indigenous categories, Northwest Argentina.

Los primeros esquemas de clasificación de la cultura prehispánica del noroeste argentino, en los Andes del sur, comenzaron tempranamente y abarcaron las definiciones iniciales de estilos cerámicos: draconiano, santamariano, etc. Luego, las designaciones de áreas culturales y períodos delimitaron universos de estudio y permitieron distinguir puntos focales de innovaciones culturales o de difusión de ideologías: Valliserrana, Selvas Occidentales ${ }^{1}$, Puna, Atacama, Tiahuanaco, Cuzco. Más tarde, los materiales arqueológicos permitieron interrogarse acerca de la existencia de una particular estrategia adaptativa y de subsistencia, distinguir "centros de domesticación" y "orígenes de los procesos civilizatorios", ordenar la relativa complejidad tecnológica y sociopolítica y conocer los procesos de jerarquización social y de integración estatal. Todo este trabajo generó clasificaciones arqueológicas, designando períodos, áreas cul- turales, regiones, tipos evolutivos, focos de difusión, etc., que han funcionado como categorías.

Pero las clasificaciones espaciales, la delimitación y la nominación de regiones, costumbres, artes, conductas y poblaciones, no son prácticas llevadas a cabo exclusivamente por antropólogos, geógrafos, arqueólogos o científicos en general. En efecto, en los Andes del sur, los mismos indígenas establecieron distinciones espaciales entre ellos:

En la percepción aymara (horizonte intermedio tardío: siglos XII-XV) del espacio, todo el sector entre Titicaca y Beni pertenecía al Umasuyu, mundo húmedo, vegetal, oscuro, concebido como "femenino" e "inferior" en la jerarquía dualista, por oposición a la "mitad" occidental, desértica, mineral, con luz intensa, el Urcusu$y u$, el "lado del cerro". Esta bipartición del

1 Museo Etnográfico, Moreno 350, 1091 Buenos Aires. cris@ netverk.com.ar 
conjunto andino por una y otra parte del "eje acuático" central parece fundarse en distinciones étnicas. Thérèse BouysseCassagne... evoca el desprecio aymara hacia esta humanidad del sector acuático y deprimida (valles): urus y puquinas rechazados por su suciedad, yungas, por su egoísmo. Cuesta abajo, ya se sale de la humanidad "inferior" para caer en el dominio de los "salvajes", los Chunchus parecidos a las fieras de las colinas selváticas. Entonces, bajo la mirada de los pastores aymaras, la humanidad andinaoriental oscila entre esos dos polos extremos: la Cultura (los urcojaque, hombres por excelencia) y la Naturaleza (animalidad) (Saignes 1985:ix).

Al referirnos a estas clasificaciones, admitimos que en tales visiones y divisiones indígenas del mundo participa el mito y, en ese sentido, funcionan como el "pensamiento mágico" o "salvaje", es decir, ese saber independiente y complementario "de ese otro sistema que constituirá la ciencia" (Lévi-Strauss 1999:30), y, en general, sostén de la legitimación de un origen o justificación de un orden "natural" de las cosas. Esas categorías de percepción y pensamiento cargan representaciones etnocéntricas que portan valores subjetivos. Los sistemas simbólicos son productos sociales; pero no sólo eso: no se limitan a reflejar las relaciones sociales, sino que también contribuyen a construirlas. Es decir, no son sólo instrumentos de conocimiento, pueden funcionar también como instrumentos de dominación (Bourdieu 1980).

A la vez, en "ese otro sistema que constituye la ciencia", la tarea de evaluación de los criterios de las ordenaciones regionales, étnicas, evolutivas, etc., que compete a la antropología, no debe pasar por alto que en la práctica social tales criterios (por ejemplo, un modo de subsistencia o producción, una tecnología, un estilo artístico, un medio ambiente particular) son también

objeto de representaciones mentales, es decir de actos de percepción y de apreciación, de conocimiento y de reconocimiento, en los que los agentes invierten sus intereses y sus presupuestos, y de representaciones materiales, en las cosas (emblemas, banderas, insignias, etc.) o en los actos, estrategias interesadas de manipulación simbólica destinadas a determinar la representación (mental) que los otros puedan hacerse de esas propiedades y de sus portadores. Dicho de otra manera, los rasgos que censan los etnólogos y los sociólogos objetivistas desde que son percibidos y apreciados como lo son en las prácticas, funcionan como signos, emblemas o estigmas (Bourdieu 1980:65).

Es decir, son objeto de valoración, la cual puede expresarse en una jerarquía social de dominios y objetos de estudio más o menos consagrados, más o menos prestigiosos, dentro de la disciplina.

Por otra parte, cuando los primeros investigadores de los Andes leyeron los relatos de los cronistas, tuvieron que enfrentar objetos que son ellos mismos el producto ya preconstruido de una interpretación dominante. Así Thierry Saignes comenta que, debido al "efecto, quizás, de este desprecio andino hacia los márgenes orientales, los instrumentos de estudio son insuficientes" (Saignes 1985:xi). Y nota que

la percepción hispánica del piedemonte [oriental] prolonga la visión andina, aymara o inca [dominante]".

Por su afán imperialista, el estado inca debe canalizar la violencia hacia el exterior, su pretensión totalizadora requiere la incorporación de todos los pueblos, incluso los "repelentes" salvajes llaneros... los últimos Incas envían sin cesar ejércitos para atravesar las colinas boscosas y reducir a sus temidos ocupantes antis, chunchos, chiriguanos quienes llenan de espanto a los cronistas andinos (Saignes 1985:xi).

Más tarde, según Saignes, "aún los estudios científicos posteriores pecan de esa terrible especialización ya evocada: las poblaciones andinas "centrales" tienen una historicidad, mientras que las poblaciones amazónicas "marginales" son condenadas a un arcaísmo inmóvil" (Saignes 1985:xiii; para el noroeste argentino, ver Ortiz y Ventura 2003, Ventura 1994). Es decir, que los primeros historiadores andinos habrían incorporado las representaciones indígenas de la geografía cosmológica y la historia mítica a sus propios modelos del pasado (Ventura 1994:302). 
Por eso no resulta extraño que, aunque la síntesis arqueológica de Palavecino (1948) evitara plantear analogías etnográficas o históricas directas, igualmente expresaba:

Al hablar de grupo cultural andino entiendo referirme a aquellos yacimientos cuyo contenido representa sin mayores déficits los rasgos fundamentales del patrimonio cultural andino, en tanto que bajo la designación de subandino, según la feliz expresión de Cooper, agrupo a aquellos patrimonios que en algún sentido capital denotan un cierto grado de pobreza respecto de aquéllos. Estos últimos pueden corresponder a grupos marginales que se conservaron en una etapa primitiva superada por los representantes típicos, o bien a grupos aculturados sólo en parte, $\mathrm{o}$ a desprendimientos viejos del núcleo central y ulteriormente depauperados.

Al grupo andino típico pertenecen los yacimientos de la Puna, los de la quebrada de Humahuaca, los de los valles del Noroeste y los del Chaco santiagueño. Los grupos subandinos forman un extenso cíngulo que se extiende de Norte a Sur al Este del área andina, separando del núcleo principal la vasta área de la llanura santiagueña. Integran el cíngulo subandino los yacimientos de Santa Victoria, explorados por Márquez Miranda, los de oriente jujeño excavados por Boman, los de la Candelaria que fueron dados a conocer por Schreiter, Métraux y Rydén, y los de las sierras de Córdoba estudiados por Outes, Aparicio y Serrano (Palavecino 1948:496) [énfasis mío].

$\mathrm{Al}$ analizar este párrafo, hoy resulta difícil establecer cuál es la medida de pobreza/riqueza que se tomó en cuenta para determinar que los yacimientos chaco-santiagueños eran más ricos en su patrimonio de rasgos andinos que los yacimientos de $\mathrm{La}$ Candelaria y, por consiguiente, unos y otros cayeran en diferentes lados de la frontera andino/subandino, rico/pobre. Esto lleva a recordar la carga de valores que puede estar encerrada en cualquier clasificación ya sea "indígena" ya sea "científica".

Una reflexión sobre el primer milenio d.C. en el valle de Santa María o Yocavil ${ }^{2}$ (Figura 1), que estudió hace un tiempo (Scattolin 2000, 2003a y 2003b), permite examinar cómo la cultura material ha sido usada para interpretar el grado relativo de desarrollo y complejidad de las poblaciones prehispánicas del noroeste argentino. Por tal camino es posible revisar si el relato resultante incorpora de manera impensada como instrumentos de conocimiento, es decir, como herramientas metodológicas para la investigación, categorías de percepción y pensamiento indígenas, cuando en realidad debería tomarlas como temas de análisis (Bourdieu 1990). En última instancia, propongo considerar que los esquemas, clasificaciones y modelos arqueológicos puedan ser examinados como clasificaciones indígenas a fin de revelar su fundamento y restarles subjetividad.

\section{Representaciones Simbólicas y Categorías Conceptuales Indígenas}

Cuando estudié la iconografía de los recipientes cerámicos del primer milenio d.C. de Yocavil en relación con conjuntos vecinos, comprobé que portaban significaciones que integraban nociones y oposiciones del espacio corporal, el espacio cósmico y el espacio social, imbricadas con ordenaciones sexuales. Al analizar las posturas del cuerpo de los individuos masculinos y femeninos representados, buscaba una vía para estudiar los sistemas simbólicos del pasado (Scattolin 2003a). Me referiré a ello brevemente.

Uno de los personajes más populares en el primer milenio d.C. del noroeste argentino, presente en la cerámica de estilo Aguada de los valles de Hualfín y Ambato, es el "guerrero-sacrificador". Esta figura podría tener múltiples aspectos manifestados por sus posturas y atributos asociados (Figura 2). Entre sus atributos más característicos está el de presentarse erguido y de frente, portar armas, hachas y cetros en sus brazos elevados, llevar trofeos de cráneos o estar cubierto con una máscara felínica. Raramente aparece con sus rasgos sexuales fenotípicos, y entonces se representan genitales masculinos. Pocas veces se ve de espaldas. Se lo asocia a la idea de un varón, potencialmente agresivo, con poderes y saberes sobrenaturales y seculares. Podría representar a un oficiante ritual o chamán-sacerdote, un líder de aspecto violento, el representante terrenal de una deidad solar andina, o más generalmente un individuo de mayor jerarquía (González 1998; Pérez Gollán 2000). 


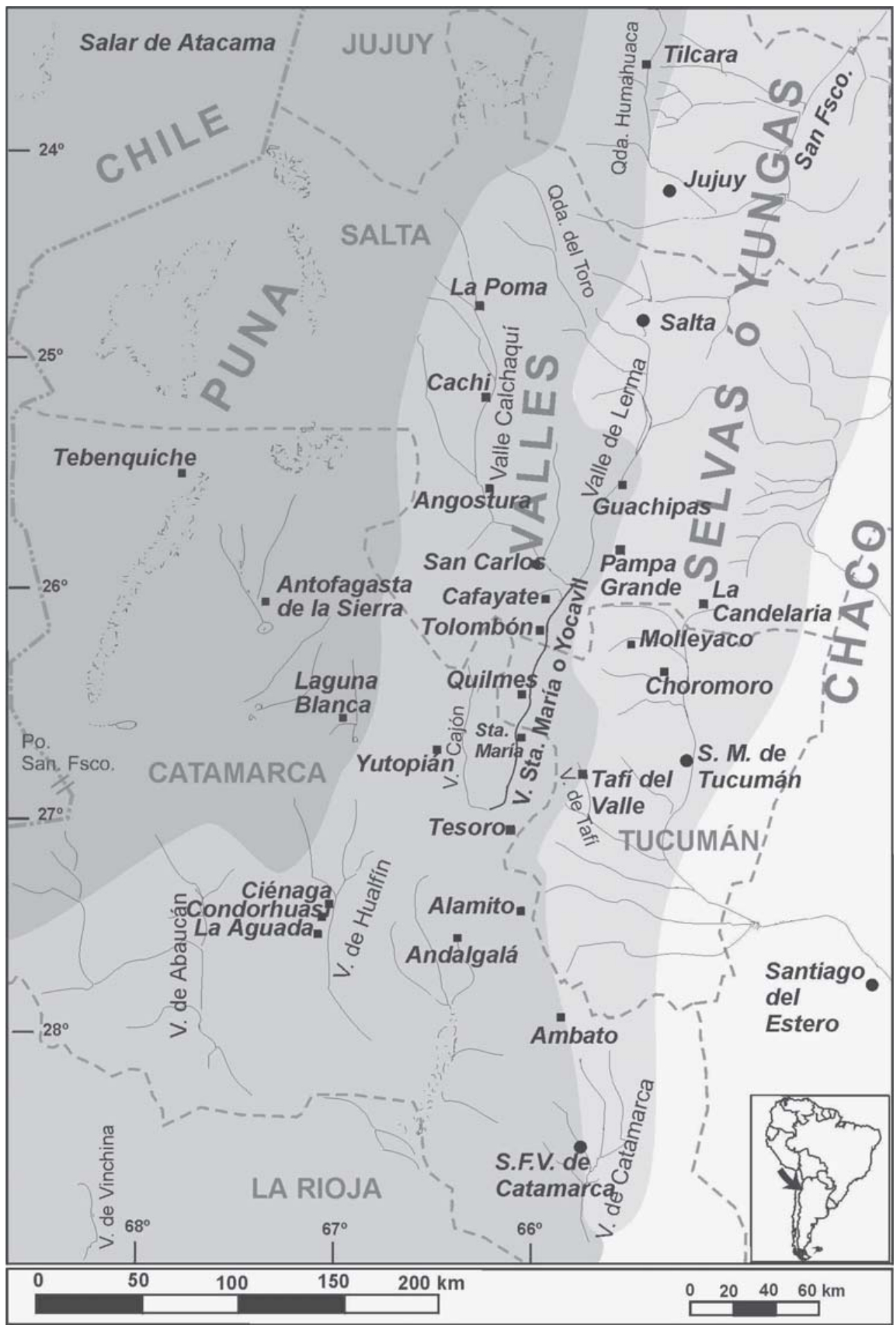

Figura 1. Noroeste argentino. El valle de Santa María y alrededores. Northwestern Argentina. Santa María Valley and surrounding areas. 

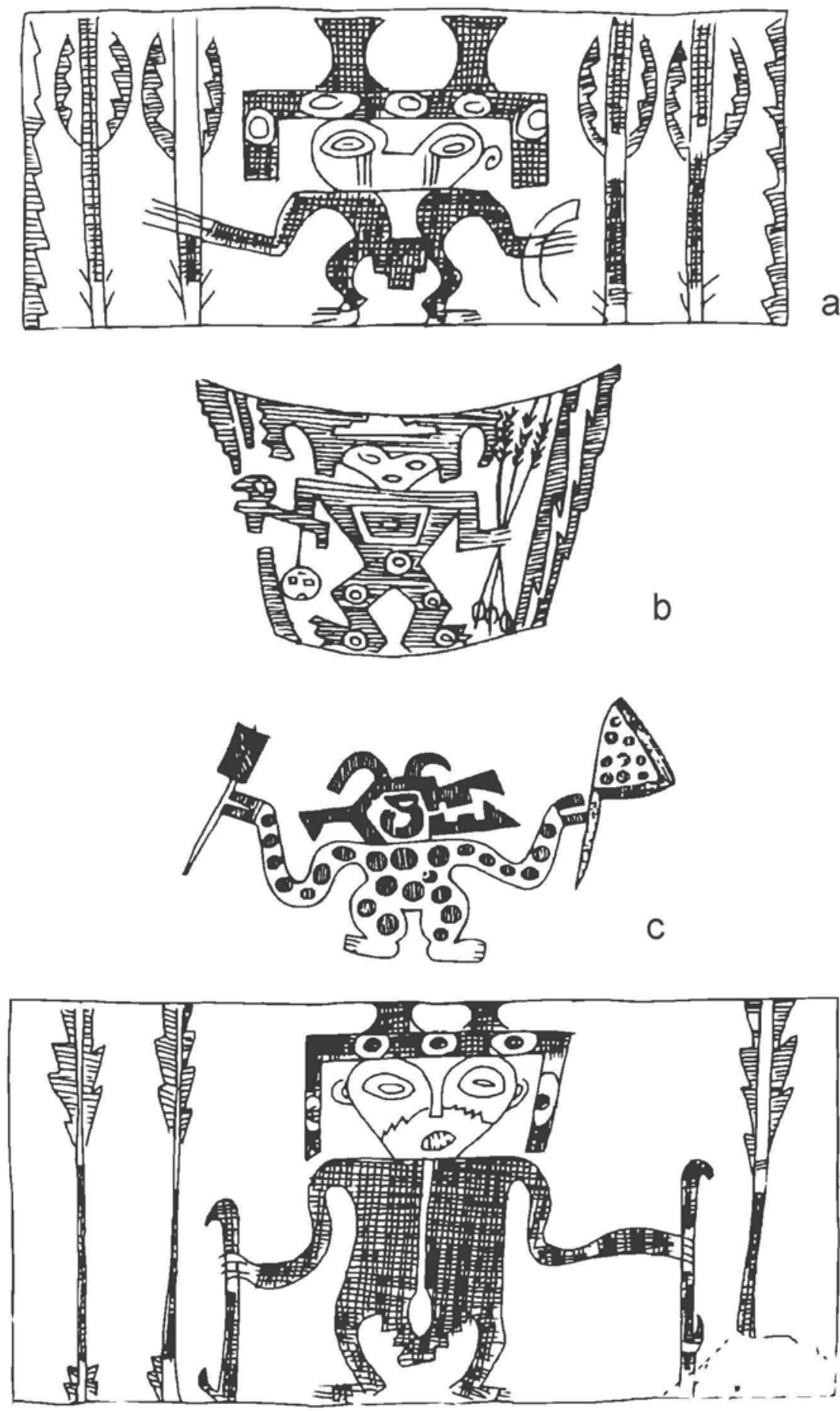

d

Figura 2. El guerrero y sus atributos: (a, b y d) valle de Hualfín; (c) Ambato (tomado de González y Baldini 1991). The warrior and his attributes: ( $a$, $b$ and d) Hualfín Valley; (c) Ambato (from González and Baldini 1991). 
El guerrero aparece en una manufactura alfarera reconocida como la más lograda en toda la historia prehispánica del noroeste argentino. Por lo común se representa bidimensionalmente, en paneles rectangulares, que se aprecian de frente, incisos o grabados sobre una superficie negra o gris pulida. Los recursos estilísticos usados se muestran convencionalizados y sugieren participación en la misma esfera simbólica de Tiwanaku. Esta cerámica porta otro de los protagonistas más reconocidos, el jaguar, o uturunco, imagen feroz que representaría una deidad de antigua raigambre andina (Pérez Gollán 2000). Hay muy escasas representaciones femeninas en la cerámica Aguada.

Tanto el guerrero como el uturunco contrastan con los motivos registrados recientemente en las colecciones de Yocavil (Scattolin 2003b). Una cuarta parte $(\mathrm{n}=79)$ de los 310 recipientes del primer milenio analizados comprende vasijas de tipo efigie. La imaginería tiende mayoritariamente a la figuración de seres humanos y aves. La mitad de los vasos efigie son antropomorfos $(n=40$, incluyendo zooantropomorfos). En general, hay rostros y cuerpos sin indicación de sexo, pero los únicos cinco casos sexuados que registré exhiben imágenes femeninas. Uno de estos vasos representa una mujer que lleva un cántaro en la espalda. Otra mujer está sentada y muestra un orificio entre las piernas y glúteos abultados apreciables de espaldas (Figura 3 a-d). Son muy populares también las efigies de aves con alas aplicadas.

En las vasijas-mujer se da la postura arrodillada, o sentada, es decir, una postura dócil. La apreciación visual es volumétrica, lateral, frontal y posterior donde se alcanzan a ver las nalgas. Además, las mujeres-vasijas aparecen en diferentes manufacturas, no sólo las más perfectamente confeccionadas. Asimismo, ningún recipiente se ha identificado como masculino, ninguna pieza presentó la imagen de "el guerrero-sacrificador" o trofeos de

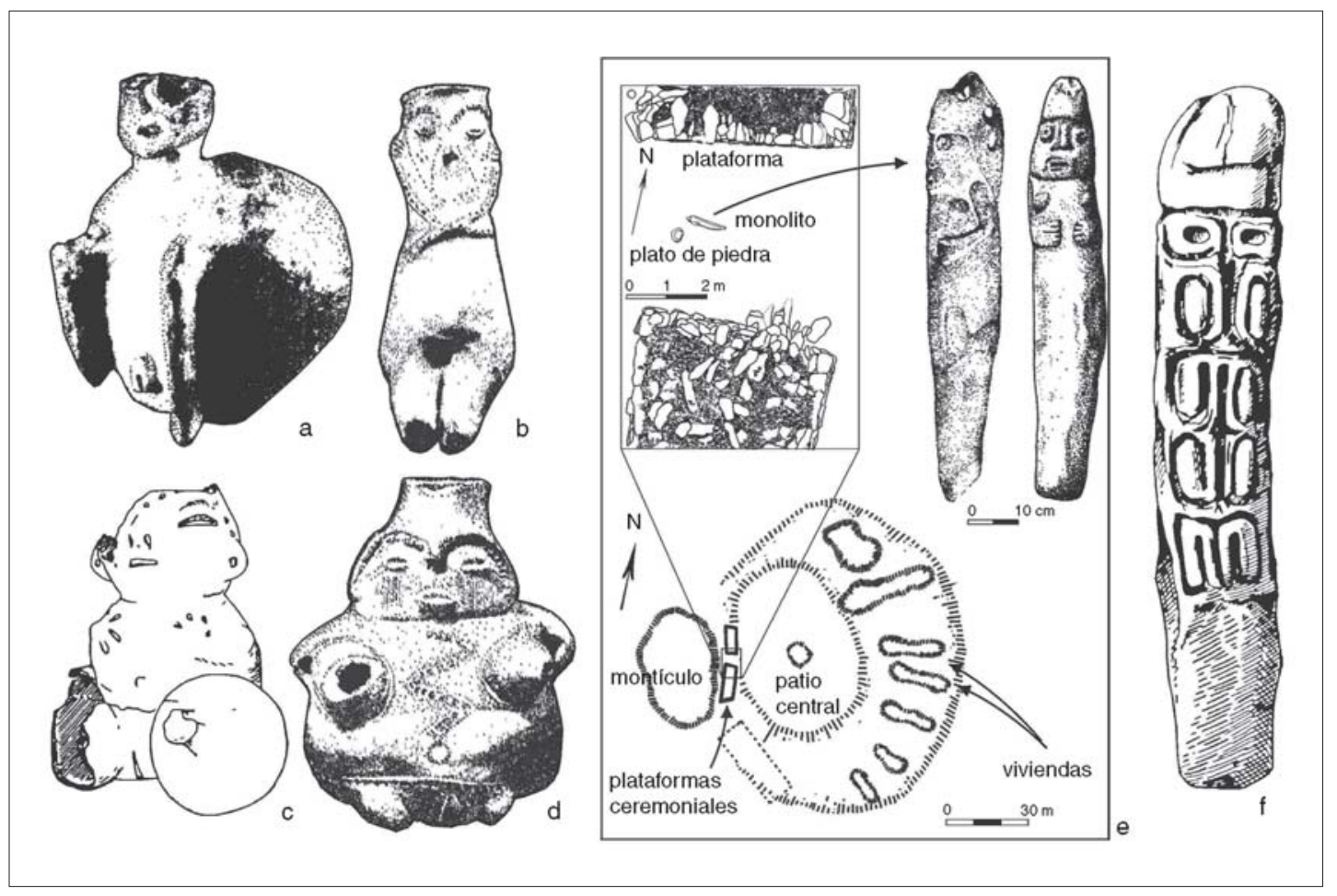

Figura 3. (a) Mujer llevando un cántaro a la espalda, gris pulido, alt. $10 \mathrm{~cm}$, Quilmes; (b) vasija-mujer, beige pulido, alt. 14,5 cm, Cafayate; (c) vasija-mujer, rojo pulido, alt. $18 \mathrm{~cm}$, Tolombón; (d) vasija-mujer, alt. 11,5 cm, Santa María; (e) monolito con figura de alter-ego, la "mujer-saurio" o "mujer-felino" entre dos plataformas de un asentamiento de Alamito; alt. $100 \mathrm{~cm}$ (González y Núñez Regueiro 1960; Núñez Regueiro 1998); (f) monolito fálico, Tafí del Valle, alt. $190 \mathrm{~cm}$ (Bruch 1911).

(a) Woman carrying a pitcher on her back, polished gray, height: $10 \mathrm{~cm}$, Quilmes; (b) woman-as-container, polished beige, height: $14.5 \mathrm{~cm}$, Cafayate; (c) woman-as-container, polished red, height: $18 \mathrm{~cm}$, Tolombón; (d) woman-as-container, height: 11.5 $\mathrm{cm}$, Santa María; (e) freestanding stone pillar with alter-ego representation, "saurian woman" or "feline woman" between two platforms at an Alamito site; height: 100 cm (González and Núñez Regueiro 1960; Núñez Regueiro 1998); (f) phallic monolith, Tafí del Valle, height: $190 \mathrm{~cm}$ (Bruch 1911). 
cráneos y "el felino" es notable por su escasez y excepcionalidad.

Aparte de las vasijas, la expresión material de la asignación de estatus y posiciones en el espacio social durante el primer milenio se manifiesta también en el uso de distinciones sexuadas en objetos ostensibles ubicados en espacios abiertos, como los monolitos sexuados de Alamito (González y Núñez Regueiro 1960:143) o de Tafí del Valle, fuera de Yocavil (Bruch 1911). Estos monolitos constituyen expresiones materiales objetivadas de estrategias de inversión simbólica convenientes para aumentar el capital de reconocimiento de una cierta categoría social en relación con un orden sexuado.

Estos postes líticos se manifiestan en el espacio comunal colectivo de la unidad doméstica, familia, linaje, clan, grupo de parentesco o etnia, y así contribuyen a instituir los principios que fundan las diferencias estatutarias y, a la vez, sexuadas entre segmentos sociales (Figura 3e, f). De modo similar, las representaciones sexuadas en cerámica de alta calidad, v.g., de estilo Aguada, asociadas a estructuras ceremoniales, sugieren estrategias similares a nivel comunitario o supracomunitario.

En este sentido, las ubicaciones de los objetos en un espacio cargado de significaciones -que engloban oposiciones como arriba/abajo, superior/ intermedio/inferior, oeste/este, alto/bajo, cerro/llano, celeste/terrestre, recto/curvo, derecha/izquierda, etc.- podrían haber funcionado como operadores de distinción entre segmentos sociales tales como las expresadas por los términos conceptuales históricamente particulares de hanan/hurin o urco/uma usados en el área andina durante los siglos XII a XV, pero que podrían tener origen en épocas más remotas (Saignes 1985:ix). Estos conceptos, que han sido estudiados como elementos fundamentales del sistema simbólico del área andina, operan como en cualquier esquema cognitivo: organizan una visión del mundo, pero a la vez cumplen, asimismo, funciones políticas, normalmente legitimando una visión construida desde el punto de vista del grupo dominante (Bourdieu 1990).

Así, la expresión material de los gestos y actividades asociadas a cada sexo en la cultura material aquí descritas constituyen una forma de objetivación que distribuye atributos posturalesespaciales-corporales de fácil, casi directa connotación valorativa a cada uno de ellos, lo cual permite elaborar distinciones categoriales. Una vez que tales prácticas sexuadas quedaban objetivadas en las cosas, se daban entonces unas condiciones óptimas para que ciertas categorías pudieran ser usadas en estrategias de inversión simbólica encaminadas a asegurar o mantener la legitimación de la dominación y de su fundamento (Bourdieu 1994). Es decir, que ciertos objetos pueden ser empleados como medios materiales para contribuir a producir y reproducir desigualdades persistentes. Pueden funcionar como representaciones de mitos, esos saberes sin ciencia, destinados a la justificación o legitimación de un orden natural de las cosas.

En el noroeste argentino la dimensión sexual de la cultura material pudo activarse para proyectar la estructura de las relaciones sociales y -junto con ordenaciones espaciales (anatómicas, corporales, geográficas, topográficas), temporales (antepasados remotos y recientes), de parentesco (dadores y tomadores de mujeres), etc.- estaba a disposición como uno de los clivajes privilegiados para proyectar la estructura de relaciones sociales, económicas y simbólicas que condujo a la institucionalización de jerarquías sociales. El análisis precedente podría considerarse entonces como una aproximación al sistema de clasificación/categorización de aquellas poblaciones y, al mismo tiempo, a sus sistemas de imposición de un orden. ¿Cuál ha sido a su vez el esquema arqueológico usado para clasificar esas sociedades aldeanas?

\section{El Yocavil del Primer Milenio en las Distribuciones Arqueológicas}

En 1948 también Wendell Bennett dio a conocer su propuesta de ordenamiento de la arqueología del noroeste argentino, pero más despojada de valoraciones que la de Palavecino. Bennett dividió el noroeste argentino en cuatro áreas -norte, centro, sur y este- que estaban formuladas sobre la base de distribuciones de estilos cerámicos. $\mathrm{Al}$ área centro, abarcada por los valles de Santa María, Calchaquí, Lerma, parte de la Puna y de las Yungas, le atribuyó los estilos Candelaria y Tafí (Bennett et al. 1948). Consignó, además, que en Yocavil también estaban representados los estilos definidos más tarde por González (1963) en Hualfín: Ciénaga y Aguada. Éstos eran compartidos con el área sur, que Bennett delimitó desde Hualfín hacia el sur.

En 1963 González presentó un mapa cultural diferente que tuvo gran aceptación. Distinguió un área valliserrana que incluía los valles Calchaquí y Yocavil junto con el de Hualfín y otros hacia el 
sur, constituyendo la región con las culturas más adelantadas y pioneras (González y Pérez 1972:28) a la que más tarde se adicionó la región de Ambato (González 1998). Aparte quedaban las Selvas Occidentales (las Yungas), Humahuaca, la Puna y la región Chaco-Santiagueña. Organizando los espacios jerarquizadamente, González consideraba a la selva como zona periférica desde donde se introducían conflictos desintegradores en la secuencia progresiva de evolución (Quiroga 2003). Tal evolución habría tenido su punto culminante con el desarrollo de la cultura Aguada, la que nunca habría sido sobrepasada:

El proceso evolutivo, a nivel continental, prosiguió en la Región Andina Central. Allí los pueblos y culturas alcanzaron el nivel estatal o aún imperial de las sociedades complejas. Es evidente que este no fue el caso de las culturas del N. O. Argentino, que no superaron en esta fase preinca el nivel de desarrollo tecnológico, religioso y socio-político de Aguada... Las culturas de este período [de 1000 a 1450], no sobrepasaron el grado de complejidad socio-política que tuvo Aguada (González 1998:285, 1999:298).

El mapa de González (1963) se combinaba con un cuadro cronológico. A los períodos Temprano y Medio les asignó, en Calchaquí-Yocavil, la misma sucesión que delimitó en su "secuencia maestra" del valle de Hualfín, esto es, Condorhuasi, Ciénaga y Aguada; pero, contrariamente a Bennett, descartó la presencia de los estilos Candelaria-Tafí. Vale decir, González asoció más el valle Yocavil a los desarrollos ocurridos hacia al sur y no tanto a aquellos ocurridos más al norte, al oeste o al este. Desde entonces la idea de que en Santa María-Calchaquí deberían esperarse los mismos estilos cerámicos definidos en la "secuencia maestra" -Ciénaga y Aguada-, parece mantener preponderancia. A esto último se suma el hecho de que las investigaciones sobre el primer milenio en Yocavil fueron muy discontinuas, lo que contribuyó a que se cristalizara una idea que revela una ansiosa expectativa por hallar los mismos estilos cerámicos que en Hualfín:

Arqueológicamente, el Valle de Santa María es casi desconocido para el Perío- do Medio o Formativo... En el Valle de Santa María no se encuentran asentamientos Aguada importantes ... tampoco hay aglomeraciones grandes de esa cerámica en superficie. De todos modos algunos fragmentos Aguada se encuentran en muchos sitios, pero no hay evidencias de ocupación Aguada intensa. ¿Qué hubo entonces? ¿Un vacío difícil de imaginar u otras culturas? (Podestá y de Perrota 1976:46).

Al parecer, no encontrar restos de la cultura Aguada resultaba decepcionante y señal decisiva de una carencia que había que explicar. Algunos autores han considerado la posibilidad de que los valles de Santa María y Calchaquí hayan tenido manifestaciones culturales distintas a las de las culturas Ciénaga y Aguada. Entre ellos Heredia llegó a postular la existencia de una cultura llamada San Carlos, que habría sido la contraparte equivalente a la cultura Ciénaga de Hualfín, pero su propuesta no alcanzó difusión (Heredia et al. 1974 citado en Tarragó y Scattolin 1999). Tarragó sugirió la presencia de una tercera esfera de interacción entre Aguada e Isla, "donde ocurren producciones cerámicas correspondientes a Candelaria III (Molleyaco, Rupachico y afines)", la cual involucraría una parte del valle Yocavil (Tarragó 1984:126, 1989:479; Tarragó y Scattolin 1999), pero tampoco ha tenido mayor aceptación (Tartusi y Núñez Regueiro 2001). Prevalece, en cambio, la idea de que el único foco de desarrollo pionero y progresivo está asociado a la expansión del estilo artístico Aguada, el cual seguramente debió difundirse en múltiples direcciones; últimamente el foco se lo ubica en el valle de Ambato (González 1998 y 1999; Núñez Regueiro y Tartusi 2002; Pérez Gollán 2000). En los últimos años presté atención a estas ideas previas y analicé cómo habían sido estudiados los personajes de la iconografía durante la trayectoria temporal del primer milenio.

\section{Categoremas Indígenas y Categoremas Científicos}

A medida que conocimos más del guerrerosacrificador de la cerámica Aguada, se fue desdibujando desde la época de los primeros arqueólogos la imagen femenina, reconocida casi exclusivamente en el estilo Candelaria (Scattolin 2003a). Más recientemente, como adelantamos, se ha ve- 
nido sosteniendo que las poblaciones de AmbatoHualfín habrían sido las promotoras del cambio principal hacia la jerarquización social en la historia prehispánica del noroeste argentino, y un foco de innovaciones sociales, de integración regional y de difusión de la ideología de la deidad felínica y del guerrero-sacrificador.

Este interés por la jerarquización social se ha dado en los últimos años y es correlativo de una declinación del trabajo en el área sur de las Yungas. Quizá debido a ello ha habido una gradual ampliación de la distribución del estilo Aguada (compárese González 1964: Figura 1 y Núñez Regueiro y Tartusi 1993: Figura 1) mientras que el estilo Candelaria ha quedado confinado a la selva, indicando que la desigual información entre áreas puede afectar nuestra percepción de los procesos, y, además, que puede haber objetos de estudio "consagrados" que atraen mayor interés que otros menos atendidos.

En cuanto a la imagen femenina, Heredia (1974), el estudioso de la cultura Candelaria, casi no resaltó su importancia en este estilo. En cambio, Rex González (1977) describe el estilo y la imaginería femenina en base a una mujer-vasija (Figura 3d). Y, sin embargo, las implicancias procesuales, ideológicas o sociológicas de las figuras femeninas no se han abordado como en el caso del guerrero, incluso contando con datos bioantropológicos sugerentes de esqueletos sexuados (Baffi et al. 1996).

Esta constricción de los estudios en la zona sur de las Yungas ha sido paralela a la falta de investigación, desde los años sesenta, del registro arqueológico del primer milenio de Yocavil. Recién ahora el estudio de colecciones de Yocavil muestra que las imágenes del guerrero y del felino no fueron muy usadas en la alfarería y, por el contrario, muchas de las vasijas de Yocavil comparten, además, atributos con cerámica de las Yungas. Esto indica que durante la segunda parte del primer milenio, entre 500 y 900 d.C., las fuerzas de cambio reflejadas en la cultura material no parecen imprimir los mismos efectos que se dan más al sur con la difusión de motivos decorativos asociados al estilo Aguada o con el mencionado fenómeno de integración regional (Scattolin 2003b).

Este panorama reclama estar alerta acerca de la cristalización de conocimientos desigualmente profundos y elaborados con herramientas teóricas y metodológicas desarrolladas desigualmente en las investigaciones de las diferentes partes del noroeste argentino.

Este proceso se comprueba con el siguiente hecho: explícitamente nunca se impugna que, en términos históricos, la tradición estilística Candelaria sea contemporánea de la tradición Aguada y, sin embargo, en la práctica educativa y en la narrativa arqueológica, y en un sentido evolutivo-procesual, siempre se ha descrito a la "cultura Candelaria" (y también a la "cultura Tafí"), en primer lugar, junto con otras sociedades aldeanas antiguas, como un precedente de las sociedades jerárquicas y con antelación a la "cultura Aguada", aunque todavía no hay estudios que se hayan ocupado de explorar si hubo o no procesos de jerarquización social en los sitios que presentan cerámica de estilo Candelaria.

Por otra parte, es notorio que los conjuntos de artefactos de La Candelaria y valle de Tafí sean conocidos por compartir ciertos rasgos estilísticos comunes y por su cercanía geográfica, aunque siempre hayan sido tratados como dos culturas diferenciadas. Este tratamiento contrasta con aquel que se ha hecho respecto a los conjuntos de artefactos de Hualfín, Ambato, valle de Catamarca, La Rioja, etc., que comparten también ciertos rasgos estilísticos, pero que han sido considerados como pertenecientes a una única entidad cultural, "Aguada" (con variantes regionales). Hasta lo que conozco no hay estudios que hayan investigado si las diferencias entre los conjuntos materiales de $\mathrm{La}$ Candelaria y valle de Tafí son más acusadas que las diferencias que separan a los conjuntos materiales de Hualfín, Ambato, valle de Catamarca, etc., como para justificar tal dualidad en la consideración de los datos. Así que es difícil establecer cuál es la medida de integridad/fragmentación cultural que los arqueólogos del noroeste argentino toman en cuenta para determinar, por ejemplo, que la "cultura Aguada" es una y que las "culturas Candelaria y Tafí" son dos. De manera que las razones de este tratamiento dual son inciertas, aunque podría ser un subproducto impensado de la historia de las investigaciones que merecería un estudio. Ello sugiere reconsiderar cuál es el grado real de integración/fragmentación así como de complejidad social que efectivamente afecta a las poblaciones consumidoras de objetos de estilo Aguada y aquellas consumidoras de objetos de estilo Candelaria-Tafí.

Por eso, habría que evitar la cristalización o rutinización de una serie de ideas y de asociacio- 
nes no explicitadas que se deslicen impensadamente y que se condensen como esencias para pintar un cuadro de las sociedades aldeanas del noroeste argentino, como la que quedaría expresada en el esquema siguiente:

Andes: masculino: innovación: jerárquico: complejo, evolucionado; Aguada: período Medio: integración, Selvas: femenino: continuidad: igualitario: primigenio: Candelaria: período Temprano: fragmentación

Este esquema resulta curioso al compararlo con el esquema cognitivo aludido al principio y atribuido al mito aymara (Saignes 1985:ix):

Occidente: masculino: desértico: mineral: luminoso: superior: Urcosuyu

Oriente: femenino: húmedo: vegetal: oscuro: inferior: Umasuyu

Tal comparación pone de manifiesto que los esquemas de conocimiento empleados dentro de la disciplina se fundan en similares principios de representación simbólica que los de las antiguas poblaciones y, por lo tanto, están predispuestos estructuralmente para reproducir e incorporar impensadamente en la práctica arqueológica las categorías de conocimiento/esquemas míticos y la subjetividad de las estructuras cognitivas de las poblaciones indígenas, en vez de tomarlas como objeto de estudio.

Así, algunos de los conceptos y nominaciones que predicamos de las poblaciones del primer milenio -andino, yunga, Aguada, Candelaria, integración, fragmentación, período Medio, período Temprano, igualitario, jerárquico, complejo, evolucionado, etc.- no están vinculados necesariamente por relaciones unívocas y estereotipadas ${ }^{3}$ y podrían no estar apropiadamente validados. Al mismo tiempo, al ser "percibidos y apreciados como lo son en las prácticas", pueden estar sujetos a valoraciones subjetivas que lleven a considerar ciertos temas más o menos visibles y valorables como objetos de es- tudio ${ }^{4}$, es decir, pueden funcionar como "representaciones mentales" más dependientes de los esquemas indígenas de pensamiento mágico -en el sentido de los indígenas del pasado, y de nosotros, como indígenas contemporáneos- que de investigaciones metódicamente controladas. Entiendo, como dice Hobsbawm, que

todos los historiadores, sean cuales sean sus objetivos, están comprometidos en el proceso [de invención de tradiciones] en tanto que contribuyen, conscientemente o no, a la creación, desmantelamiento y reestructuración de las imágenes del pasado que no sólo pertenecen al mundo de la investigación especializada, sino a la esfera pública del hombre como ser político. Deberían ser conscientes de esta dimensión de sus actividades (Hobsbawm 2002:20).

Por eso creo que nuestras clasificaciones y categorías pueden ser también un objeto de estudio que deberíamos investigar, tal como la antropología ha investigado los sistemas cognitivos de los indígenas como dispositivos de pensamiento salvaje ${ }^{5}$. Porque si las clasificaciones arqueológicas escapan a la vigilancia metódica, podrían funcionar como signos emblemáticos o estigmatizadores, es decir valoraciones -"indígenas", "salvajes"- que no hagan más que reiterar los puntos de vista ya superados que en un momento se sostuvieron dentro de la disciplina -como los de la época de Palavecino- o prolongar, como decía Saignes, la visión dominante, andina, aymara o inka, que tales pueblos tenían de las poblaciones que intentaban subordinar, instaurando un mito fundacional o justificando un orden "natural", es decir, arbitrario, de las cosas.

Agradecimientos: A los revisores anónimos por sus respetuosos comentarios. Espero haber sorteado en alguna medida mis dificultades para expresar mis ideas, que parecen haber confundido a uno de ellos. 


\section{Referencias Citadas}

Baffi, E., M.F. Torres y J. Cocilovo

1996 La población prehispánica de Las Pirguas (Salta, Argentina). Un enfoque integral. Revista Argentina de Antropología Biológica 1:204-218.

Bennett, W., E. Bleiler y F. Sommer

1948 Northwest Argentine Archaeology. Yale University Publications in Anthropology, 38. London.

Bourdieu, P.

1980 L'identité et la représentation. Élements par une réflexion critique sur l'idée de région. Actes de la Recherche en Sciences Sociales 35:63-72.

1990 La domination masculine. Actes de la Recherche en Sciences Sociales 84:2-31.

1994 Stratégies de reproduction et modes de domination. Actes de la Recherche en Sciences Sociales 105:3-12.

1999 [1975] Método científico y jerarquía social de los objetos. En Intelectuales, Política y Poder, traducido y compilado por A. Gutiérrez, pp. 147-151. Ed. Eudeba, Buenos Aires.

Bruch, C.

1911 Exploraciones arqueológicas en las provincias de Tucumán y Catamarca. Revista del Museo de La Plata XIX. González, A.R.

1963 Cultural Development in NW Argentina. En Aboriginal Development in Latin America: An Interpretative Review, editado por B. Meggers y C. Evans, pp. 103-117. Smithsonian Miscellaneous Collection, Washington.

1964 La cultura de La Aguada del N.O. Argentino. Revista del Instituto de Antropología 2-3:205-253.

1977 Arte Precolombino en la Argentina. Filmediciones Valero, Buenos Aires.

1998 Arte Precolombino. Cultura La Aguada. Arqueología y Diseños. Filmediciones Valero, Buenos Aires.

1999 La cultura de La Aguada y el período Formativo. Evolución e historia en el proceso cultural del Noroeste argentino. En Formativo Sudamericano, una Revaluación, editado por P. Lederberger-Crespo, pp. 285-301. Editorial Abya Yala, Quito.

González, A.R. y M. Baldini

1991 Función y significado de un ceramio de la cultura La Aguada. Ensayo de interpretación. Boletín del Museo Chileno de Arte Precolombino 5:23-52.

González, A.R. y V. Núñez Regueiro

1960 Apuntes preliminares sobre la arqueología del Campo de Pucará y alrededores (Dpto. Andalgalá, Pcia. de Catamarca). Anales de Arqueología y Etnología XIV$\mathrm{XV}: 115-162$.

González, A.R. y J.A. Pérez

1972 Argentina Indígena. Vísperas de la Conquista. Paidós, Colección Historia Argentina I, Buenos Aires.

Heredia, O.

1974 Investigaciones arqueológicas en el sector meridional de las Selvas Occidentales. Revista del Instituto de Antropología 5:73-132.

Heredia, O., M. Palacios, A. Luzzi y L. Naudeau

1974 Ensayo de un cuadro cronológico del sector meridional del Valle Calchaquí. Ponencia presentada en el III Congreso Nacional de Arqueología Argentina, Salta.
Hobsbawm, E.

2002 [1983] Introducción: la invención de la tradición. En La Invención de la Tradición. Traducido por O. Rodríguez, editado por E. Hobsbawm y T. Ranger, pp. 7-21. Editorial Crítica, Barcelona.

Lévi-Strauss, $\mathrm{C}$.

1999 [1962] El Pensamiento Salvaje. Traducido por F. González Arámburu. FCE, México.

Núñez Regueiro, V.

1974 Conceptos instrumentales y marco teórico en relación al análisis del desarrollo cultural del Noroeste argentino. Revista del Instituto de Antropología 5:169-190.

1998 Arqueología, Historia y Antropología de los Sitios de Alamito. Ed. Interdea, Tucumán.

Núñez Regueiro, V. y M. Tartusi

1990 Aproximación al estudio del área pedemontana de Sudamérica. Cuadernos 12:125-160.

1993 Orígenes de la ocupación prehispánica del sitio StucTav 5 (El Pichao), Provincia de Tucumán. Publicaciones 2:19-30.

2002 Aguada y el proceso de integración regional. Estudios Atacameños 24:9-19.

Ortiz, G. y B. Ventura, editoras

2003 La Mitad Verde del Mundo Andino. Investigaciones Arqueológicas en la Vertiente Oriental de los Andes y las Tierras Bajas de Bolivia y Argentina. Editorial de la Universidad de Jujuy, Jujuy.

Palavecino, E.

1948 Áreas y capas culturales en el territorio argentino. Gaea VIII: 447-523.

Pérez Gollán, J.

1991 La cultura de La Aguada vista desde el valle de Ambato. Publicaciones del Centro de Investigaciones de la Facultad de Filosofía y Humanidades 46:157-173.

1994 Los Sueños del Jaguar. Viaje a la Región de la Sabiduría y los Señores Iluminados. Museo Chileno de Arte Precolombino, Santiago.

2000 El jaguar en llamas (La religión en el antiguo Noroeste argentino). En Nueva Historia Argentina: I. Los Pueblos Originarios y la Conquista, dirigido por M. Tarragó, pp. 229-256. Ed. Sudamericana, Buenos Aires.

Phillips, P., J.A. Ford y J.B. Griffin

1951 Archaeological Survey in the Lower Mississippi Alluvial Valley, 1940-1947. Peabody Museum of American Archaeology and Ethnology, Papers 25, Harvard University.

Podestá, C. y E. de Perrota

1976 Desarrollo cultural en el Valle de Santa María durante el Período Tardío o de Desarrollos Regionales. Revista del Museo de Historia Natural, Tomo III (1/4):43-54.

Quiroga, L.

2003 Belén. Debates en torno a la construcción de un objeto de estudio. Runa 24:151-172.

Raffino, R., G. Raviña, L. Baldini y A. Iácona

1982 La expansión septentrional de la cultura La Aguada en el N.O. argentino. Cuadernos 9:179-82.

1994 El NOA y la integración Inka (1471-1535 d.C.). Rumitacana 1:43-48.

Saignes, T.

1985 Los Andes Orientales. Historia de un Olvido. IFEA CERES, La Paz. 
Scattolin, M.C.

2000 Santa María durante el Primer Milenio A. D. ¿Tierra Baldía? Arstryck 95-98:63-83.

2003a Representaciones sexuadas y jerarquías sociales en el noroeste argentino prehispánico. Acta Americana 11:30-48.

2003b Los ancestros de Calchaquí: una visión de la colección Zavaleta. Cuadernos 20:51-79.

Tarragó, M.

1984 La historia de los pueblos circumpuneños en relación con el Altiplano y los Andes Meridionales. Estudios Atacameños 7:116-132.

1989 Contribución al Conocimiento Arqueológico de los Oasis de San Pedro de Atacama en Relación con Otros Pueblos Puneños, en Especial el Sector Norte del Valle Calchaquí. Tesis doctoral, Facultad de Humanidades y Artes, Universidad Nacional de Rosario.
Tarragó, M. y C. Scattolin

1999 La Problemática del período Formativo en el Valle de Santa María. Actas del XII Congreso Nacional de Arqueología Argentina, Tomo I:142-153, La Plata.

Tartusi, M. y V. Núñez Regueiro

2001 La presencia de La Aguada en la Provincia de Tucumán, Argentina. Trabajo presentado a la IV Mesa Redonda "La cultura de La Aguada y su dispersión". 11-14 de octubre del 2000. San Pedro de Atacama. http:www.geocities. com/aguadamesaredonda, (junio 2003).

Ventura, B.

1994 Un verde horizonte de sucesos. En Taller de Costa a Selva, editado por M.E. Albeck, pp. 301-328. Instituto Interdisciplinario Tilcara. Universidad de Buenos Aires, Tilcara.

\section{Notas}

1 En la Argentina se denomina Selvas Occidentales o Sierras Subandinas a la vertiente oriental andina.

2 Debido a la existencia de distintas versiones en la terminología de la cronología arqueológica del noroeste argentino, he preferido referirme a un tramo temporal neutro como el del primer milenio d.C., a pesar de que uno de los revisores anónimos me sugirió que me "acotara a la propuesta cronológica de González", al parecer la de mayor difusión fuera de la Argentina. La trayectoria temporal de lo que denomino laxamente como primer milenio d.C. es simultánea y paralela del desarrollo del centro urbano de Tiwanaku durante el período Intermedio Temprano y el Horizonte Medio del área Centro Sur andina, términos que, por una peculiar tradición nacional, en Argentina no se utilizan. Una parte del primer milenio en el noroeste argentino fue denominada por A. Rex González período Temprano (600 a.C. a 650 d.C.) y otra parte como período Medio (650 a 850 d. C.), que reconoce como jalón la ocurrencia de materiales atribuidos a la "cultura Aguada". Raffino los denominó Formativo Inferior y Superior, y también propuso el término de período Clásico para el estadio más avanzado del Formativo (Raffino et al. 1982:33; Raffino 1994:46). Aparte de Raffino, otros autores consideraron también como período Formativo el lapso entre 600 a.C. y 1.000 d.C. (Núñez Regueiro 1974). En el valle Santa María abarca los componentes arqueológicos agroalfareros anteriores al período Tardío o de los Desarrollos Regionales (900 a 1.450 d.C.) con cerámica de estilo santamariano, recordando que en el contexto argentino, cuando se habla de período Tardío (González 1963), se alude al período Intermedio Tardío del área Central Sur andina. Tampoco utilizo el término período de Integración Regional, que se usa al sur del área aquí tratada, particularmente los valles de Hualfín, Ambato, Abaucán y La Rioja, para referirse a procesos asociados a la dispersión del estilo Aguada, que se desarrollan dentro del lapso de 300 a 950 d.C. (Núñez Regueiro y Tartusi 1990, 2002; Pérez Gollán 1991, 1994), en razón de que los restos materiales atribuidos a este estilo no están muy representados en el valle de Santa María.
3 Así, por ejemplo, nunca está de más insistir que "Aguada" y "período Medio" no son términos intercambiables, aunque el uso rutinario o ambiguo de esas dos nociones lleve a confundirlas o a acoplarlas.

4 Y de paso, más o menos retribuyentes de beneficios simbólicos para aquellos que se orientan con buen "sentido práctico". Hay, evidentemente, algunos temas de estudio que "pagan más", es decir, brindan mayores recompensas materiales y simbólicas. "La jerarquía de los dominios y de los objetos orienta las inversiones intelectuales por mediación de la estructura de las posibilidades (medias) de beneficio material y simbólico que ella contribuye a definir: el investigador participa siempre de la importancia y del valor que es comúnmente atribuido a su objeto, y hay muy pocas posibilidades de que él no tome en cuenta [tal valor], consciente o inconscientemente, en la ubicación de sus intereses intelectuales" (Bourdieu 1999:148).

5 Las persistencias del "pensamiento mágico" dentro de la arqueología se manifiestan incluso en las recomendaciones ofrecidas, hace más de medio siglo, por los autores del siguiente párrafo, quienes nos recuerdan, en el "lenguaje de la magia", que los tipos cerámicos y, por ende, otras categorías arqueológicas, son construcciones arbitrarias que vienen a ser tratadas "mágicamente" como unidades empíricas "reales":

"Exigencies of language require us to think and talk about pottery types as though they had some sort of independent existence. 'This sherd is Baytown Plain'. Upon sufficient repetition of this statement, the concept Baytown Plain takes on a massive solidity. The time comes when we are ready to fight for dear old Baytown. What we have to try to remember is that the statement really means something like this:

'This sherd sufficiently resembles material which for the time being we have elected to call Baytown Plain'. Frequent repetition of this and similar exorcisms we have found to be extremely salutary during the classificatory activities" (Phillips et al. 1951:66). 